\title{
Eesti keele ja kultuuri õpetamisest Oulu ülikoolis
}

\author{
HELI LAANEKASK
}

Tartu Ülikool

Ülevaade. Kujunes traditsioon, et neis Soome ülikoolides, kus soome keelt õpetatakse peaainena, kuulub eesti keel õppekavasse lähisugulaskeelena; lektoriteks on enamasti olnud eestlastest õppejõud. Aastal 1958 rajatud Oulu ülikoolis alustati soome keele peaainega 1966. a, eesti keele lektori ametikoht kinnitati alates 1.9.1967. Oulus otsustati lektor hankida Eestist (mujal Soome ülikoolides olid eesti keele lektoriteks kas enne Teist maailmasõda või sõjakeerises Soome asunud eestlased). Bürokraatlike ja ideoloogiliste takistuste kiuste hakati mujalegi Soome ülikoolidesse kutsuma lektoreid Eestist. Nõukogude Liit lubas eesti lektoreid Soome vaid üheks-kaheks, hiljem kolmeks-neljaks õppeaastaks. Okupatsioonist vabanenud Eestist valiti Oulu ülikooli uus eesti keele lektor 1992. aastal ametisse juba tavapärase konkursi korras. Kokku on aastatel 1967-2016 Oulus eesti keele lektorina töötanud 15 õppejõudu, neist kaheksa Tartu ülikoolist ja neli Tallinna pedagoogilisest instituudist. Esialgsesse õppekavva kuulusid eesti keele alg-, järg- ja vestluskursus ning eesti kirjanduse kursus. 1987. aastal sai eesti keel ja kultuur Oulus kõrvalaineks (võimalik sooritada alamastme õpingud, 1997. aastast ka keskastme õpingud). Külalisõppejõududena on Oulus esinenud tuntud Eesti haritlasi; õpetust on toetanud mh ka Eesti haridus- ja teadusministeerium. Oulu eesti keele lektorid on aktiivselt osalenud rahvusvahelises teadustöös ja Eesti-Soome kultuurivahetuses ning aidanud luua positiivset Eesti-kuvandit Soomes ja Soome-kuvandit Eestis. Eesti keele ja kultuuri kõrvalaine õpetamine lõpetati Oulu ülikoolis 
(nagu mitmes Soome ülikoolis varem) rahapuuduse tõttu. 2014. aasta sügissemestrist töötab Oulus eesti ja soome keele lektor, kes lisaks soome keele ainetele õpetab ka eesti keele alg- ja järgkursust. Tasapisi on eesti keele ja kultuuri õpetus taas laienemas.

Võtmesõnad: eesti keele õpetus soomlastele; eesti keel ja kultuur välismaal; Soome eestlased; Oulu ülikooli eesti keele lektoraat; kontrastiivne keeleuurimine; eesti-soome kultuurisuhted; soome keel; eesti keel

\section{Tagasivaade ajaloole}

Detsembris 2017 oleks Oulus põhjust poolesajandipeoks: täitub 50 aastat päevast, kui Oulu ülikoolis alustas tööd eesti keele lektor. Nagu ikka, on igal sündmusel oma eellugu.

Teatavasti asutati maailma esimene eesti ja soome keele lektoraat just meie auväärse Tartu ülikooli juurde 1803. aastal. 1802 taasavatud Tartu ülikool oli siis Vene keisririigi ainuke luterlik ülikool ja pidi vähemalt kavatsuslikult andma ka teoloogilist haridust kogu Venemaa luterlikule alale, st tulevastele pastoritele ka eestikeelsel Eesti- ja Liivimaal ning soome- ja soomesugukeelsel Ingerimaal ja Viiburi läänis. (Tamul 2003: 21-23; Viitso 2003: 281) Lektoraadi loomisele aitas kaasa ka tolleks ajaks juba üldtunnustatud teadmine eesti ja soome keele sugulusest. Tartus oli esimeseks selliseks lektoriks - algse ametinimetusega eesti ja Soomemaa keele lektor (Lector der Ehstnischen und Finnländischen Sprache), hiljem eesti ja soome keele lektor (Lector der Ehstnischen und Finnischen Sprache) - Tartu Jaani koguduse ülempastor, baltisakslane Friedrich David Lenz. Tollase õppekava andmetel õpetas ta esimesel kolmel semestril vaid eesti keelt, kuid edaspidi, kuni oma surmani 1809. aastal, nii eesti kui (võib-olla) ka soome keelt. Lenzi loengute sisu lühikirjeldustes soome keele õpetusest nimelt siiski ei räägita. (Aabrams 2003: 36) Vormiliselt oli eesti ja soome keele lektor veel ka tema ametijärglane Georg Philipp August von Roth (1810-1817), kuid pole andmeid, et Roth oleks õpetanud soome keelt. Nimelt oli Venemaa 1808.-1809. aasta 
sõjas anastanud Soome, Venemaa keisrist oli saanud ka Soome suurvürst. Et ka Turu ülikool oli luterlik, siis Tartu ülikooli teeneid soomekeelse ala jaoks pastorite ettevalmistamisel enam ei vajatud. (Viitso 2003: 281-282) Lenzi ja Rothi töö jätkajate ametinimetuseks Tartu ülikoolis oli juba eesti keele lektor.

Vastavalt sellele, kuidas tugevnes võrdlev-ajaloolise keeleteaduse paradigma, laienes aegamööda ka sugulaskeelte tutvustamine-õpetamine Eesti ja Soome ülikoolides. Näiteks esimene Helsingi ülikooli soome keele lektor Carl Niclas Keckman on 1830. aastatel oma loengutes tutvustanud ka eesti keelt (Pääkkönen 1994: 76-77); Tartu ülikooli neljas eesti keele lektor Johann Samuel Friedrich Boubrig on 1820. aastate lõpul soovitanud oma kuulajatele kirjandust soome keele tundmaõppimiseks (Laanekask 2013: 154). Ajapikku nõuded kasvasid, näiteks Helsingi ülikoolis pidi soome keele ja kirjanduse approbatur'i saavutamiseks 1920. aastate alguses tundma ka eesti grammatika põhijooni ja lugema vähemalt $100 \mathrm{lk}$ eestikeelset teksti; vastavalt oli ka õppekavas loenguid ja harjutustunde, mida pidasid soomlastest õppejõud (Grünthal 1999: 16).

Esimene eesti keele lektori ametikoht Soomes loodi Helsingi ülikooli juurde aastal 1923, kusjuures eeldati, et tulevane lektor peab eesti keelt valdama emakeelena. Ametisse valitigi eestlane, Helsingi ülikoolis 1911. aastal magistrikraadi saanud, seejärel Eestis töötanud ja Tartu ülikooli stipendiaadina Helsingis doktoritööd kirjutanud Villem Grünthal (kirjanikunimega Ridala), kes tegutses sellel kohal kuni oma surmani aastal 1942. (Grünthal 1999) Tartu ülikoolis pidas spetsiaalseid soome keele kursusi esimesena Mihkel Veske 1870.-1880. aastatel; soome keele lektoraat alustas Tartus tegevust 1920. aastal, lektori kohuseid täitis siis Hilja Kettunen (kuni 1924), edasi Aino Suits (kuni 1944). (Viitso 2003: 282-296)

Komme, et eesti keelt Soome ülikoolides ópetavad emakeelsed õppejõud, püsis Soomes enamasti ka pärast Teist maailmasõda, näiteks 1960. aastate lõpul töötasid Helsingis Eeva Niinivaara, Turu ülikoolis Martta Päkkilä, Jyväskyläs Leho Võrk (Kasik 2003: 361). Eestiski ei lakanud soome ja teiste soome-ugri keelte tõhus ülikooliõpe - olgu siinkohal 
tänuga mainitud eestlastest õppejõud Paula Palmeos, Paul Ariste, Paul Alvre jt. Soomlasest lektor jõudis Tartusse pärast pikemat vaheaega taas alles siis, kui okupatsioon juba murenes. Esimene selliste õppejõudude auväärses reas oli Jussi Kallio, kelle esimene õpetusperiood Tartu ülikoolis kestis 1989-1992. (Viitso 2003: 296-300)

\section{Uuendusmeelne Oulu ülikool ja okupeeritud Eesti}

Oulu ülikool alustas tegevust aastal 1958; soome keelt peaainena hakati Oulus õpetama 1966. aasta sügisest. 1967. aasta kevadsemestri kavas olnud eesti keele algkursuse õpingud korraldati veel suveülikooli raames, kuhu lektoriks oli palutud auväärne Eeva Niinivaara Helsingi ülikoolist. Just sellel suvekursusel alustas muide oma eesti keele ja kultuuri õpinguid tudengineiu Helena, praegune Oulu ülikooli emeriitprofessor Helena Sulkala.

On niisiis vana traditsioon, et kõikjal Soome ülikoolides, kus soome keel on kavas peaainena, kuulub eesti keel kui lähisugulaskeel kohustuslikku õppekavva. Eesti keele õpetamisega Oulus kaasneb siiski see tähelepanuväärne seik, et Oulu on esimene Soome ülikoolidest, kuhu pärast Teist maailmasõda hangiti lektor Eestist - Nõukogude Eestist, nagu tol ajal öeldi. Muudes Soome ülikoolides töötavad eestlased olid kas juba enne sõda Soome tulnud või siis sõjakeerises Eestist lahkunud inimesed.

1939.-1941. aasta Nõukogude okupatsioon jätkus Eestis 1944. aastast ja karm metafoor "raudne eesriie" sobib paraku iseloomustama seda isolatsiooni, kuhu okupeeritud Eestit püüti suruda. Totalitaarses riigis oli info levik rangelt kontrollitud ja filtreeritud. Eriti tiheda ideoloogilise sõela läbis ametlik avalik teave Eesti mineviku ja oleviku kohta. Ka üksikisikutevahelist infovahetust püüti kontrollida, takistada ja ainulubatud tõlgendusmalli suruda. Eriti ohtlikuks peeti kõike, mis tuli "mandunud, imperialistlikust" Läänest, olgu see Lääs siis sõjajärgne finlandiseeruv Soome või iseseisvamat poliitikat ajav Rootsi. Rootsis elavad eestlased, samuti Kanadas jm lääneriikides elav eestlaskond, pejoratiivselt "emigrandid", olid ametliku ideoloogia poolt eriti vaenatud. 
Päris hermeetiliseks ei suudetud seda raudset eesriiet siiski kunagi muuta. Sellesse teemasse pikemalt süvenemata nendin, et 1967. aastaks, kui Eestist saabunud eesti keele lektor Oulus alustas, oli see totaalne isolatsioon mõnevõrra leevenenud. Muu hulgas oli mõranemise märk see, et Eestis ei suudetud takistada nt Soome raadio- ja eriti televisioonisaadete levi. 1964. aastal käis Soome president Urho Kaleva Kekkonen Eestis ja pidas Tartu ülikooli aulas eestikeelse kõne. 1965. aastal taastati regulaarne laevaühendus Eesti ja Soome vahel. Eesti keele lektori tulek Eestist Oulusse oli osa samast protsessist.

\section{Eesti keele lektoraadi loomine Oulu ülikooli ja raskusi Eestist lektori saamisel}

Tegelikkuses oli lektori kutsumine Eestist Oulusse siiski vaevaline, sest asja üle otsustajaid oli hämarates võimukoridorides liiga palju ja lõplik otsus langetati mitte Eestis või Soomes, vaid Moskvas (Kingisepp 1992: 75; Kasik 2003: 361-363). Tollal Oulu ülikooli soome keele professori kohuseid täitnud Matti Pääkkönen (2006) meenutab, et teaduskonnas oldi mõnevõrra hämmastunud, kui ta 1967. aasta kevadsemestril teatas, et õppeaine vajab püsivat eesti keele lektorit, kes peab olema emakeelne. Juunikuus tuli teade haridusministeeriumist, et lektoraadi loomine võimaldatakse riigi lisaeelarve toel, Pääkkösel tuli kirjutada veel ametlik põhjendus. 1967. aasta sügissemestrist professorina alustanud Pauli Saukkonen oli see, kes otsustas, et lektor hangitakse Eestist. Taotlus esitati Soome-Nõukogude Teaduslik-Tehnilise Koostöökomisjoni kaudu üleliidulisele haridusministeeriumile Moskvas, kust seni oli välismaale lähetatud vaid vene keele õpetajaid. Nõukogude bürokraatiamasina aeglust mäletades tundub see koguni saavutusena, et esimene lektor Ellen Noot siiski jõudis sügissemestri lõpuks detsembri alguses Oulusse ja alustas loengutega 5. detsembril 1967, päev enne Soome iseseisvuspäeva (Helena Sulkala suuline teade Heli Laanekasele). Kuulajateks oli sada üliõpilast ja õppetöö jätkus intensiivses vormis kuni jõuludeni. Kevadsemestril kulgesid õpingud juba tavatempos. 
Kuna Nõukogude Liit ilmselt pidas pikemaajalist välismaal viibimist oma alamate lojaalsusele ohtlikuks, kestis esimese "päris" lektori Ellen Nooda tööaeg Oulus praktiliselt vaid pool aastat. Järgmise lektori saamine Eestist nõudis uusi ponnistusi. Matti Pääkkönen (2006) meenutab, et Oulu ülikooli eesti keele lektoraat oli kinnitatud alama palgaastme ametikohaks 1. septembrist 1967 ning aegsasti oli läkitatud taotlus järgmise lektori hankimiseks. Kui nüüd 1968. aasta oktoobri keskel lektorist veel kippu ega kõppu ei kuuldunud, saatis kõlbmatust asjaajamisest nördinud Pauli Saukkonen otse Moskva haridusministeeriumisse venekeelse kirja, kus teatas, et kui lektorit Eestist ei saada, on ta sunnitud kutsuma lektori Rootsi pagulaseestlaste seast. Kiri oli nii mõjus, et lektoriks vist juba varem sobivaks arvatud Ago Künnap võetud kaasa oma Tartu ülikooli töökohalt, lennutatud Moskvasse ja sealt Helsingi kaudu Oulusse, nii et Künnap jõudnud talviselt lumesajusesse Oulusse pintsakuväel, peas nokkmüts ja kaenlas portfell. Õppetööd alustas ta 25. oktoobril 1968.

Välistest takistustest hoolimata tundus asi ise - lektori tulek Eestist sedavõrd positiivsena, et aegamööda hakati peaaegu kõikidesse Soome ülikoolidesse, kus eesti keelt oppetati, kutsuma lektoreid Eestist. Nende nn külalislektorite tööaeg pikenes kahe, kolme, hiljem koguni nelja óppeaastani.

\section{Oulu ülikooli eesti keele lektorid ning eesti keele ja kultuuri akadeemiline õpe}

Oulu ülikoolis on eesti keele lektorina tegutsenud Ellen Noot (Tallinnast, 1967-1968), Ago Künnap (Tartust, 1968-1969), Ülo Parbus (Tartust, 1969-1972), Aino Valmet (Tartust, 1972-1974), Reet Kasik (Tartust, 1974-1976), Hoide Sikk (Tallinnast, 1976-1978), Heldi Tamm (Tallinnast, 1978-1980), Mart Mäger (Tallinnast, 1980-1983), Jaak Peebo (Tartust, 1983-1984), Peep Nemvalts (Tallinnast, 1984-1988), Valve-Liivi Kingisepp (Tartust, 1988-1992), Heli Laanekask (Tartust, 1992-2014), Ele Süvalep (Tartust, 2007-2009), Ulla Paukkunen (Oulust, 2014) ja Maria Frick (Helsingist, 2014-). 
Oulus on eesti keele lektorina töötanud õppejõude nii Tartu ülikoolist kui ka Tallinna pedagoogilisest instituudist (praegune Tallinna ülikool). Vaid esimene lektor Ellen Noot oli asutusest nimega Välismaaga Sõpruse ja Kultuurisidemete Arendamise Ühing, kus ta muu hulgas oli tegutsenud tõlgina ja giidina. Veebruarist 1972 muudeti Oulu lektorikoht kõrgema palgaastme lektoraadiks (Kingisepp 1992: 76; Pääkkönen 2006), mis tähendas, et ametisse valitu pidi olema vähemalt litsentsiaadikraadiga (tolleaegses Eestis kandidaadikraadiga).

1992. aasta sügisel oli mul au olla esimene eesti keele lektor, kes sai Oulusse tulla okupatsioonist vabanenud Eestist, kohale päriselt kandideerides ja valituks saades. Kõik Oulu eesti keele lektorid töötasid tähtajaliste töölepingutega kuni aastani 2000, mil koht kuulutati alaliseks ja sellele valiti Heli Laanekask. 2007. aasta sügissemestrist kuni 2009. aasta kevadsemestrini olin Oulust palgata puhkusel ja töötasin Tartu ülikoolis, sel ajal oli Oulus eesti keele lektoriks Ele Süvalep. Paraku läks majandussurutise tõttu ka Oulus nii, nagu varem oli juhtunud mõnes teiseski Soome ülikoolis: kui senine Oulu lektor jäi 2014. aastal pensionile, siis lõppes ka eesti keele ja kultuuri ainete õpetamine senises mahus. 2014. aasta sügissemestrist on ametis praegune eesti ja soome keele lektor Maria Frick, kes lisaks soome keele ainetele õpetab ka eesti keele alg- ja järgkursust. 2014. aasta sügissemestril oli Maria Frick lapsepuhkusel ja tema asemel õpetas eesti keele algkursust Ulla Paukkunen.

Oulu ülikooli eesti keele õppekavasse on algusest peale kuulunud alg- ja järgkursus, eesti kirjanduse kursus ja vestluskursus (Kingisepp 1992: 77). Õpetuseks vajalikke materjale on koostanud lektorid ise, eriti algul, hiljem on olnud võimalik kohandada või osaliselt kasutada ka teiste poolt loodut. Kursustest osavõtt on olnud algusest peale rõõmustavalt elav. Näiteks esimene lektor Ellen Noot on meenutanud, et ta pidas 1968. aasta kevadsemestril oma iganädalast tunnipikkust eesti kirjanduse loengut kesklinnas Päästearmee suures saalis (ülikool tegutseski siis veel eri kohtades kesklinnas, Linnanmaad polnud veel ehitatud) ja saal oli puupüsti täis, nii et osa publikust kuulas loengut püsti seistes. Omalt poolt võin öelda, et mu viimastel lektoriaastatel tuli algkursusele 
ikka umbes 50-60 üliõpilast, neist ligi pooled jätkasid järgkursusel ja neist omakorda pooled pürgisid sooritama alamastme õpinguid. Keskastme õpingute sooritajaid oli juba vähem, ehk paar-kolm üliõpilast aastas, sageli just need, kes olid õppinud Eestis vahetustudengitena.

Eesti keele õpinguõigus oli esialgu ametlikult vaid humanitaarteaduskonna üliõpilastel, kuid õppetöös on ikka osalenud ka ülikooli töötajaid ning teiste teaduskondade tudengeid. Hiljem oli õpinguõigus kõigil Oulu üliõpilastel. 1987. aastast peale oli eesti keel ja kultuur Oulus kõrvalaineks, millest oli võimalik sooritada approbatur, st alamastme õpingud (Kingisepp 1992: 77), 1997. aastast peale aga ka keskastme õpingud (Laanekask 2002: 48-50). Kõrvalaine õppekava uuendati aastate vältel korduvalt, kuid mahud jäid enam-vähem samaks. Näiteks 2013.2014. õppeaasta eesti keele õppekavva kuulusid eelópingud ehk 4-ainepunktiline eesti keele algkursus, mis üksiti liitus kohustuslikuna soome keele keskastme õpingute hulka (NB! ainepunkt tähendab praeguses ülikoolis umbes 27-tunnilist töömahtu, kuhu on arvatud nii kontaktõpetus kui ka üliõpilase iseseisev töö); edasi eesti keele alamastme õpingud (25 ainepunkti, aineteks järgkursus, vestlus- ja kirjutuskursus ning kursused eesti keele varieerumisest, eesti kirjandusest, eesti kultuuri ja eesti keele küsimustest) ja keskastme õpingud (35 ainepunkti, aineteks vastavalt kursused tänapäeva eesti keele grammatikast, eesti leksikoloogiast, eesti kirjanikest, eesti tôlkest, eesti rahvatraditsioonist ning lisaks eesti keele ja kultuuri valikaineid). Kokku võis soovija eesti keelest ja kultuurist sooritada niisiis 64-ainepunktilise tsükli. Bakalaureusekraadi (soome kandidaatintutkinto) eesti keele alal Oulus siiski sooritada ei saanud.

Õpetuskeelena kasutati õpingute algul soome ja eesti keelt, pärast vestlus- ja kirjutuskursust aga juba enamasti vaid eesti keelt. Keskastme õpingud olid eestikeelsed, kaasa arvatud nende raames kirjutatavad üliõpilastööd. Soome keele professoritega läbi rääkides võisid üliõpilased eesti keele ja kultuuri kursusi kasutada ka soome keele kesk- ja ülemastme õpingute valikainetena ja seda tehtigi meelsasti.

Eesti keele kursusi on Oulu lektorid pidanud ka suveülikooli või avatud ülikooli raames Oulus, Rovaniemel, Raahes, Kajaanis jm. Eesti 
taasiseseisvumise järel oli Oulu eesti keele lektoril võimalik käia eesti keelt õpetamas mujalgi: olen eesti keele ja kultuuri tutvustusloenguid pidanud Norras Alta ülikoolis, Rootsis Uppsala ja Umeå ülikoolis ning Saksamaal Oderi-äärses Frankfurtis ja Göttingenis.

\section{5. Õpetuse mitmekesistamisest}

On selge, et sellises mahus õpetuse andmiseks, süvendamiseks ja mitmekesistamiseks püüti Oulus kasutada kõiki võimalusi: külalislektorite loenguid, erialakirjanduse jm materjalide hankimist raamatukogusse ja kateedri kogudesse, et hõlbustada tudengite iseseisvat tööd, üliõpilaste õppeekskursioone Eestisse, vahetusüliõpilasena või praktikandina Eestis viibimist, kõike seda hea tahte, eri programmide (nt hilisem ERASMUS) või ülikoolide partnerluslepingute toel. Raamatute-ajakirjanduse hankimiseks ja külalislektorite kutsumiseks vajalikud rahalised vahendid tuli pikkade aastate vältel leida ülikooli alati nappivast kassast, kasutades nt külaliste puhul lisaks kolleegide sõbralikku abi majutamisel, sõidutamisel ja toitlustamisel (olgu veel kord tänatud Tauno ja Elsa Lähteenkorva, Matti ja Irmeli Pääkkönen, Helena Sulkala perega, Marketta Harju-Autti, Aulikki Lappalainen, Harri Mantila jt). 1980. aastatel osteti kateedrile Leeni Ploompuu-Vesterineni eesti raamatukogu, mis sisaldas palju eesti vanemat väärtkirjandust koos pühenduskirjutistega (nt Tammsaare "Juudit" dedikatsiooniga "Laane Leenile Oru Antonilt" jts). Uuel aastasajal saime raamatuid ka annetustena kohalikelt eesti keele sõpradelt, näiteks Irmeli ja Matti Pääkkönenilt, emakeeleõpetaja Maina Kiviojalt ja eriti väärtusliku kingitusena paari tuhande köitelise kogu Tauno Lähteenkorvalt, kus samuti oli huvitavaid pühenduskirjutisi. Need raamatud on praeguseks hajutatuna Oulu ülikooli pearaamatukogus, osa neist ruumipuudusel ka kogust kõrvaldatud.

Eesti taasiseseisvumise järel hakkas pisitasa tõhustuma Eesti riigi toetus eesti keele ja kultuuri akadeemilisele välisõppele, nii et viimastel aastatel oli võimalik lisaks teatud hulga kirjanduse tellimisele saada toetust ka vähemalt ühe külalislektori kutsumiseks semestris ning 
paari üliõpilase osalemiseks eesti keele ja kultuuri suvekursustel Eestis. 1990ndatest peale oli võimalik Eestisse õppima minna juba ka üliõpilasvahetuse kaudu, tavaliselt üheks-kaheks semestriks. On selge, et Eestis õppimine lihvib ja lisab tudengite keeleoskust ning süvendab kultuuri tundmist. Mis puutub külalislektoritesse, siis on Oulus õpetamas käinud näiteks Paul Alvre, Eduard Vääri, Ants Järv, Karl Muru, Huno Rätsep, Mati Hint, Jüri Valge, Mati Erelt, Juhan Maiste, Sirje Olesk, Anna Verschik, Annekatrin Kaivapalu, Heinike Heinsoo, Sulev Iva, Mart Velsker, Birute Klaas-Lang, Karl Pajusalu, Helle Metslang ja mitmed teised.

\section{Oulu ülikooli eesti keele lektorite teadustööst ja -kontaktidest}

Oulu eesti keele lektorite teadustöös on selgelt näha kaht suundumust. Esiteks on püütud jätkata oma varasemaid uurimissuundi, sageli nendeks uusi või värskemaid lähenemisnurki leides. Teiseks on peaaegu alati lisandunud uurimusi eesti-soome kontrastiivse keeleteaduse või kultuurisuhete alalt. Teadustöö tulemusi on võimalik olnud rakendada loengutes või harjutustundides. Kontrastiivsete uurimuste juures on saanud kätt harjutada ka üliõpilased. Samuti on võimalikud olnud teaduskontaktid Eesti ja Soome kõrgkoolide ning teadus- ja muudegi asutustega. Eesti ja soome keele õppeaine koostööpartneriteks Eestis on olnud Tartu ülikool, praegune Tallinna ülikool koos oma eelkäijatega, Eesti Keele Instituut, Emakeele Selts, Eesti Kirjandusmuuseum, Võru Instituut, Eesti suursaatkond Soomes ja Soome suursaatkond Eestis, Eesti haridus- ja teadusministeerium, Eesti Instituut, Eestis tegutsev Soome Instituut. Väga oluline on, et Eesti-kontakte tekkis Oulu ülikoolis teistelgi õpetus- ja uurimisaladel, näiteks ajaloolastel, arheoloogidel, kirjandusteadlastel, pedagoogikateadlastel, bioloogidel, arstiteadlastel, füüsikutel, matemaatikutel jt.

Soomes tegutsevate eesti keele lektorite koostööle ja viljakatele kontaktidele Soome kolleegidega kontrastiivse lingvistika raames aitasid palju kaasa aastal 1982 kavandama hakatud ja 1983. aastal alguse saanud 
eesti-soome veaanalüüsiseminarid, mida hakati korraldama eesti keele õpetust andvate Soome ülikoolide juures. Haarde laienedes ja kõrvutavate uuringute süvenedes on vastavaid teaduskohtumisi 1989. aastast peale peetud eesti-soome kontrastiivseminaride nime all. Asja juures tegutses algusest peale Hannu Remes, Joensuu ülikooli pikaaegne eesti ja soome keele lektor. Tema koos Valma Yli-Vakkuriga toimetas ka esimese kogumiku, mis sisaldas seminariettekannete põhjal kirjutatud artikleid ja ilmus 1983. aastal Tampere ülikooli soome keele ja üldkeeleteaduse kateedri väljaannete sarjas. 1985. aastal Joensuu lähedal Mekrijärvel peetud seminari ettekandeid ilmus Turu ülikooli soome ja üldkeeleteaduse kateedri toimetiste sarjas. See kogumik (toimetajaks taas Hannu Remes) kandis professor Päivi Rintala antud head pealkirja "Lähivertailuja", mis siitpeale ongi püsima jäänud, algul Soome ja Eesti eri ülikoolide väljaandena, praeguseks aga Eesti Rakenduslingvistika Ühingu poolt välja antava ajakirjana pealkirja all "Lähivõrdlusi. Lähivertailuja". (Remes 2015) Oulu ülikooli eesti keele lektorid koos oma soome kolleegidega on korraldanud vastavaid seminare aastatel 1987, 1994 ja 2003 ning osalenud toimetajana "Lähivõrdlusi. Lähivertailuja" numbrite 3 (1988), 8 (1998), 14 (2004) ja 15 (2004) väljaandmisel. 2015. aasta lõpus ilmus Tallinnas "Lähivõrdluste" 25. number, milles muu hulgas on avaldatud Valve-Liivi Kingisepa teaberohked ja emotsionaalsed mälestused tema Oulu-aastatest (Kingisepp 2015).

Oulu eesti keele lektorid on osalenud ka fennougristikakongressidel, Soome keeleteaduse päevadel ning muudel teadusfoorumitel nii Soomes, Eestis kui ka mujal. Lisaks teadusartiklitele on eesti-soome kontrastiivset vaatenurka kasutatud ka mitmetes Oulu ülikooli soome keele bakalaureuse-, magistri- ja litsentsiaaditöödes ning ka Oulus kaitstud doktoritöödes, viimaste autoriteks Helle Metslang, Sirje Hassinen, Hannu Remes ja Leena Nissilä. Soome-eesti kõrvutava uurimissuuna primus motor oli Oulus aastaid praegune soome keele emeriitprofessor Helena Sulkala. 


\section{Eesti keele ja kultuuri hea sõnumi levimisest väljaspool ülikooli}

Oulu on kõige põhjapoolsem Soome ülikoolidest, kus õpetatakse eesti keelt. Kõik Oulu eesti keele lektorid on palju tegutsenud ka väljaspool ülikooli. On peetud eesti keele kursusi nii rahvaülikoolides kui ka Soome seltside või asutuste-ettevõtete juures. On kirjutatud eesti keelt ja kultuuri tutvustavaid ajaleheartikleid, koostatud raadiosaateid, esinetud koolides, raamatukogudes, koguduste üritustel ja seltsides-huviringides. On korraldatud raamatu- ja kunstinäitusi ning kontserte, tegutsetud tõlkide, tõlkijate ning giididena. Selline rahvavalgustustöö on vastanud Põhja-Soome ühiskonna ootustele, vajadustele ja huvile ning langenud viljakale pinnasele: Oulus ja laiemalt Põhja-Soomes on palju häid eesti keele oskajaid, eesti kultuuri tundjaid, eesti keele õpetajaid, Eesti sõpru.

Oulus on tegutsenud ja tegutsevad ka mitmed eesti muusikud, neist tuntumad ehk linnaorkestri dirigendina töötanud Peeter Lilje ja Arvo Volmer. Oulu kandi koorilauluharrastajad tunnevad kindlasti koorijuhte Ahti Seppa või Mihkel Kolditsat. Soome eestlastest elanikkond on jõudsalt kasvanud ka Oulus ja selle ümbruses: siin töötab eesti arste, õpetajaid, treenereid, IT-inimesi ja muude elualade esindajaid. Soome eestlaste koondumisele ja eneseteadvuse tõusule püüdsin Oulus töötades jõudumööda kaasa aidata: olin kohalikke eestlasi koondava Oulu Eesti Klubi üks asutajaliikmeid (klubist on praeguseks välja arenenud mitteametlik koostöö- ja sõprusvõrgustik oma Facebooki lehega) ning tegin kaastööd Soome eestlaste väljaannetele Eesti Leht ja Binokkel, mis omal ajal Tamperes ilmusid.

\section{Häid koostööpartnereid Oulus}

Oulu ülikooli eesti keele lektoraadi väga heaks koostööpartneriks on aastate vältel olnud ajaleht Kaleva eesotsas selle juhtide ja tippajakirjanikega: Aaro Korkeakivi, Martti Ursin, Teuvo Mällinen, Seija Hänninen, Kaisu Mikkola jt. Kaleva kaastöölisteks-kolumnistideks on olnud 
mitmed tuntud Eesti kultuuritegelased, olgu nimetatud näiteks hilisem Eesti president Lennart Meri, kirjanik Jaan Kaplinski, professorid Mati Hint, Rein Veidemann jt. Kaleva toimetusmajas leiduv esinduslik eesti kunstikogu on heaks tunnistuseks lehe Eesti-pädevusest. Kaleva on Eesti Rahvuskultuuri Fondi juurde asutanud ka omanimelise rahastu demokraatliku ajakirjanduse toetamiseks.

Koos Kalevaga ning soome keele ja kirjanduse kolleegidega Oulu ülikoolist on eesti keele lektoraat korraldanud neli eesti luule tõlkevõistlust (1978 Under, 1981 Vaarandi, 1988 Runnel, 1997 Ristikivi), iga kord on ilmunud tõlkekogumik, Underi luulest koguni kaks (vt lähemalt Sikk 1999). Kalevaga lähedalt seotud kirjastus Pohjoinen on avaldanud tõlkes muudki eesti ilukirjandust.

Väga hea koostöö on lektoritel olnud Soomes eesti kultuuri tutvustava ja toetava Tuglase Seltsiga, eriti selle Oulu haruorganisatsiooniga ehk Oulu Tuglase Seltsiga. Koostööd on tehtud ka omaaegse Põhjamaa Eesti Seltsiga, kelle liikmete ristivanemasuhted eesti lastekodulastega on olnud püsivad ja südamlikud. Rõõmuga on eesti keele lektorid osalenud ka Oulus aset leidnud Soome ja Eesti luuletajate kohtumise Runon silta Luulesild korraldamises: luulesillal on Oulus seni kokku saadud aastatel 1986, 1996, 2006 ja 2016. Head koostööpartnerid on olnud ka Oulu ülikooli raamatukogu ja Oulu linna- ning maakonnaraamatukogu, samuti ka rahvaülikool Oulu-opisto. (Vt ka Mikkola 2014)

\section{Positiivse kuvandi loomine}

Koos kõigi Oulus töötanud eesti keele lektoritega Eestist rõhutagem, et Soomes veedetud aastad on meie jaoks olnud erakordselt tähtsad ja rikkad. On olnud tõeline eesõigus esindada oma maad ja rahvast, jagada selle kohta teadmisi vastuvõtlikule ning sõbralikule sugulasrahvale ning nii mõnigi kord näha omagi keelt ja kultuuri ning omaenda ellusuhtumist uuest, värskest vaatenurgast. Oleme saanud tundma õppida Soomet just tema inimestega sõbrunedes, inimsaatuste kaudu ning Soome elust vahetult osa saades. Oleme püüdnud tegutseda nii, et tekiks positiivne 
Eesti-kuvand Soomes ja Soome-kuvand Eestis. Olge tänatud, armsad õppurid, kolleegid, koostööpartnerid ja sõbrad! Lootkem kõik, et praegu Oulu ülikooli juures tegutsev eesti ja soome keele lektoraat võiks olla uue tõusu algus eesti keele ja kultuuri tutvustamisel Põhja-Soomes.

\section{Kirjandus}

Aabrams, Vahur 2003. Friedrich David Lenz ning tema vend Jacob Michael Reinhold Lenz ['Friedrich David Lenz and his brother Jacob Michael Reinhold Lenz']. - Mati Erelt, Tiiu Erelt (Toim.), Valve-Liivi Kingisepp (Koost.), 200 aastat eesti keele ülikooliõpet. Tartu Ülikooli eesti keele õppetooli toimetised 25. Tartu: Tartu Ülikool, 28-60.

Frick, Maria 2016. Kiri Heli Laanekasele 17.11 ['E-mail'].

Grünthal, Riho 1999. Viron kielen lehtoriksi Helsingin yliopistoon 1923 ['About starting the lectureship of Estonian at the University of Helsinki in 1923']. Reet Kasik, Leena Huima (Toim.), 75 vuotta viroa Helsingin yliopistossa. Viron kielen ja kulttuurin opettaminen Suomessa -seminaari 23.11.1998. Esitelmät. Castrenianumin toimitteita 56. Helsinki: Helsingin yliopisto, 13-33.

Kasik, Reet 2003. Õppetöö välismaal ['Teaching abroad']. - Mati Erelt, Tiiu Erelt (Toim.), Valve-Liivi Kingisepp (Koost.), 200 aastat eesti keele ülikooliõpet. Tartu Ülikooli eesti keele õppetooli toimetised 25. Tartu: Tartu Ülikool, 360-369.

Kingisepp, Valve 1992. 25 vuotta viron opetusta Oulun yliopistossa ['25 years of teaching Estonian at the Oulu university']. - Helena Sulkala, Valve Kingisepp (Toim.), Viron kielen päivä 6.5.1992. Oulun yliopiston suomen ja saamen kielen laitoksen tutkimusraportteja 35. Oulu: Oulun yliopisto, 75-83.

Kingisepp, Valve-Liivi 2015. Eesti keele lektorina Oulus ['Teaching Estonian in Oulu']. - Lähivõrdlusi. Lähivertailuja 25, 35-62. https://doi.org/10.5128/ LV25.03

Laanekask, Heli 2002. Eesti keel Oulu ülikoolis ['Estonian language at the Oulu university']. - Jüri Valge (Toim.), Eesti keel ja kultuur maailmas. 13.-15. august 2000, Tartu. Ettekanded. Tartu: Eesti Vabariigi Haridusministeerium, Eesti Instituut, 44-54.

Laanekask, Heli 2013. Viron kieli toisena kielenä -opetuksesta Tarton yliopistossa 1820-luvun lopulla ['On teaching Estonian as a second language at the University of Tartu in the late 1820s]. - Lähivõrdlusi. Lähivertailuja 23, 148-162. https://doi.org/10.5128/LV23.06 
Mikkola, Kaisu 2014. Pohjoisen estofilian voima ja verkosto nousivat virolaisista lehtoreista. - Elo 4. http://www.tuglas.fi/pohjoisen-estofilian-voima-javerkosto-nousivat-virolaisista-lehtoreista (16.11.2016).

Pääkkönen, Irmeli 1994. Suomalainen sydämestä. Carl Niclas Keckmanin toiminta suomen kielen kehittäjänä ['Finn at the heart. Carl Niclas Keckman']. Helsinki: Suomalaisen Kirjallisuuden Seura.

Pääkkönen, Matti 2006. Viron lehtoreista Oulun yliopistossa ['About lecturers of Estonian at the University of Oulu']. [Käsikiri Heli Laanekase valduses.]

Remes, Hannu 2015. Lähivertailujen alkuvaiheita ['Finnish-Estonian Close Comparisons: How the story began']. - Lähivõrdlusi. Lähivertailuja 25, 15-22. https://doi.org/10.5128/LV25.01

Sallamaa, Kari 2016. E-kiri Oulu Tuglase Seltsi liikmetele 29.10 ['E-mail'].

Sikk, Hoide 1999. Virolaisen runouden käännöskilpailuista Suomessa ['The translation contest of Estonian poetry in Finland']. - Reet Kasik, Leena Huima (Toim.), 75 vuotta viroa Helsingin yliopistossa. Viron kielen ja kulttuurin opettaminen Suomessa -seminaari 23.11.1998. Esitelmät. Castrenianumin toimitteita 56. Helsinki: Helsingin yliopisto, 57-63.

Tamul, Sirje 2003. Veel kord Tartu ülikooli taasavamise ja eesti keele lektori küsimusest. - Mati Erelt, Tiiu Erelt (Toim.), Valve-Liivi Kingisepp (Koost.), 200 aastat eesti keele ülikooliõpet. Tartu Ülikooli eesti keele õppetooli toimetised 25. Tartu: Tartu Ülikool, 14-27.

Viitso, Tiit-Rein 2003. Soome keel ja läänemeresoome keelte professuur Tartu ülikoolis ['Professoriate of Finnish and Baltic-Finnic languages at the University of Tartu']. - Mati Erelt, Tiiu Erelt (Toim.), Valve-Liivi Kingisepp (Koost.), 200 aastat eesti keele ülikooliõpet. Tartu Ülikooli eesti keele õppetooli toimetised 25. Tartu: Tartu Ülikool, 281-305. 


\title{
On teaching of the Estonian language and culture at the University of Oulu
}

\author{
HELI LAANEKASK \\ University of Tartu
}

It is an established tradition that in Finnish universities where the Finnish language is taught as a main subject, the Estonian language belongs to the curriculum as a closely related language; the lecturers have mostly been Estonians. At the University of Oulu, founded in 1958, teaching of the Finnish language as the main subject began in 1966, the position of the lecturer of the Estonian language was established on 1 September 1967. In Oulu, a decision was made to invite the lecturer from Estonia; at other Finnish universities, the lecturers were Estonians who had settled in Finland before or during World War II. The Soviet Union allowed the Estonian lecturers to work in Finland only for one or two, later for three or four academic years. Despite bureaucratic and ideological obstacles, other Finnish universities also began to invite lecturers from Estonia. After the liberation of Estonia from the Soviet occupation, the new lecturer of the Estonian language was elected in 1992 by regular contest. In total, 15 people have worked as lecturers of Estonian in Oulu from 1967-2016 - eight of them from the University of Tartu and four from Tallinn Pedagogical Institute. The original curriculum included an introduction to Estonian, an intermediate course, a conversational course and a course of Estonian literature. In 1987, the Estonian language and culture became a subsidiary subject in Oulu, it was possible to take basic studies, from 1997 intermediate studies. Well-known Estonian intellectuals were invited to Oulu as visiting lecturers; teaching was also supported by the Estonian Ministry of Education and Research. The Estonian lecturers in Oulu have actively participated in international research and Estonian-Finnish cultural exchange and contributed to the positive image of Estonia in Finland and of Finland in Estonia. Teaching of the Estonian language and culture at the University of Oulu as a subsidiary subject (like in several Finnish universities earlier) was stopped because of shortage of finances. From the autumn semester 
ON TEACHING OF THE ESTONIAN LANGUAGE AND CULTURE ...

of 2014, the University of Oulu employs a lecturer of Estonian and Finnish who, in addition to Finnish language subjects, teaches the introduction to Estonian and intermediate Estonian. Slowly, the teaching of the Estonian language and culture at the University of Oulu is broadening again.

Keywords: teaching Estonian to Finnish people; Estonian language and culture abroad; Finnish Estonians; lectureship of Estonian at the University of Oulu; contrastive language studies; Estonian-Finnish cultural relations; Finnish; Estonian

\section{Heli Laanekask}

Suur kaar 60, 50404 Tartu, Estonia

heli.laanekask@ut.ee 